\title{
TRATADOS BILATERAIS DE INVESTIMENTO: CONCEITOS, POTENCIAIS IMPACTOS E TENDÊNCIAS FUTURAS
}

\author{
Ignácio Tavares de Araújo Júnior ${ }^{1}$
}

\begin{abstract}
SINOPSE
Os tratados bilaterais de investimento (TBIs) são um conjunto de normas que regulamentam os investimentos estrangeiros privados de um país em outro. 0 objetivo do TBI é prover a segurança desejável a investidores externos para estimular a entrada de investimento externo direto (IED). Este artigo faz uma revisão de uma série de trabalhos teóricos que analisam o efeito do TBI sobre o IED. De acordo com a literatura a respeito do tema, não há consenso sobre o sinal e a magnitude do impacto do TBI sobre o IED, havendo evidências apontando efeito positivo, ausência de efeito e até mesmo sugerindo impactos negativos. As tendências futuras para os TBls dão maior clareza para termos como expropriação indireta; buscam meios de resolver eventuais disputas sem a necessidade de recorrer a tribunais internacionais; e procuram evitar que, para atrair mais IED, os Estados façam concessões que entrem em conflito com objetivos de políticas domésticas que visem ao desenvolvimento sustentável.
\end{abstract}

Palavras-chave: tratados de investimento; investimento externo direto (IED).

\begin{abstract}
The bilateral investment treaties (BITs) are a set of rules that regulate private foreign investment from one country to another. The BITs aim to provide desirable security to foreign investors in order to stimulate the inflow of foreign direct investment (FDI). This article reviews a series of theoretical papers that analyze the effect of BITs on FDI. According to the literature on the subject, there is no consensus on the sign and magnitude of the impact of BITs on FDI. There are evidences suggesting a positive effect, lack of effect and even indicating negative impacts. Future trends for TBIs clarify terms such as indirect expropriation; try new ways to resolve potential disputes without the need to resort to international courts; and seek to avoid making concessions that conflict with domestic policy objectives aiming sustainable development.
\end{abstract}

Keywords: investment treaties; foreign direct investment (FDI).

JEL: F21; F23; N4.

Artigo recebido em 15/12/2020 e aprovado em 27/1/2021.

DOI: http://dx.doi.org/10.38116/bepi29art6

\section{INTRODUÇÃO}

O ingresso de investimentos externos diretos (IEDs) pode ser fonte de geração de empregos e, mais importante ainda, expôe a economia local a novas tecnologias, contribuindo para o aumento da produtividade e o crescimento econômico. Trabalhos teóricos e empíricos sugerem alguns determinantes para o ingresso de IED, tais como tamanho e qualidade do mercado, estabilidade macroeconômica, estoque de infraestrutura e dotação de fatores de produção (Blonigen, 2005). Parte da literatura sobre o tema também destaca a qualidade das instituiçôes locais, representada em grande parte pela garantia

1. Professor do Departamento de Economia da Universidade Federal da Paraíba (DE/UFPB); pesquisador do Laboratório de Economia e Modelagem Aplicada (Lema) da UFPB; e doutor em economia pelo Programa de Pós-Graduação em Economia da Universidade Federal de Pernambuco (Pimes/UFPE). E-mail: <ignacio.tavares@gmail.com>. 
de diretos de propriedade, como um importante atributo do país para ser destino de investimentos (Bénassy-Quéré, Coupet e Mayer, 2007; Buchanan, Le e Rishi, 2012). Diante do receio de ter seus ativos expropriados, as empresas tenderiam a direcionar seus investimentos para países em que os direitos de propriedade são respeitados, normalmente os já desenvolvidos. A partir do final da década de 1950, países em desenvolvimento, muitos deles apresentando instituiçóes frágeis ou sem a reputação dos países já desenvolvidos, encontraram, nos tratados bilaterais de investimento (TBIs), uma forma de sinalizar seus compromissos com os direitos de propriedade de investidores externos para então atrair mais IEDs. Ao mesmo tempo, os países desenvolvidos viram nos TBIs uma forma de proteger os investimentos de suas empresas em países com instituiçóes menos consolidadas.

Os TBIs são um conjunto de normas que regulamentam os investimentos estrangeiros privados de um país em outro. Espera-se que contribuam para a previsibilidade, a estabilidade e a transparência nas relaçóes de investimento, além de ajudar a retirar as disputas de investimentos do campo da ação diplomática de Estado para Estado para o âmbito da resolução de controvérsias baseada em leis. Os TBIs podem ajudar a melhorar os marcos regulatórios e institucionais dos países, reduzir os riscos para os investidores estrangeiros e, de forma mais geral, contribuir para melhorar o clima de investimento (UNCTAD, 2015). Acredita-se que TBIs contribuam para o aumento de IED porque indicariam que os partícipes do acordo estáo dispostos a assumir compromissos críveis de respeito aos direitos de propriedade em razáo dos elevados custos ex post resultantes do náo cumprimento das cláusulas do tratado. O TBI, além de elevar o IED entre as partes, também sinalizaria para outros países que é seguro investir naqueles que se comprometem com os termos do TBI.

Este artigo busca investigar os resultados que esses tratados podem gerar em termos de atração de novos investimentos e benefícios para a sociedade. Para alcançar esse objetivo, será realizada uma revisão da literatura teórica sobre o tema a fim de compreender em que circunstâncias os efeitos dos TBIs sobre o IED podem ficar mais evidentes. Por fim, seráo apresentadas as novas tendências para esse tipo de acordo. O Brasil, apesar de ter assinado alguns TBIs nos anos 1990, apenas em 2015 ratificou seu primeiro acordo bilateral de investimento. É importante destacar que aqueles acordos não foram ratificados devido ao receio do Congresso Nacional brasileiro a respeito de possíveis incertezas jurídicas que os TBIs poderiam trazer para o país, além de uma eventual perda de soberania notadamente sobre a adoção de políticas de interesse público que poderiam afetar direta ou indiretamente empresas estrangeiras no país (Cozendey e Cavalcante, 2015; Morosini e Xavier Junior, 2015). Para um país que necessita de maior integração internacional, conhecer as novas tendências e os benefícios e riscos inerentes a um acordo como esse pode contribuir para a formulaçáo de acordos futuros que resultem em alocaçóes de investimento mais eficientes e contribuam para o desenvolvimento do país.

A disponibilidade de dados macroeconômicos sobre os fluxos de IED tem permitido avaliar se de fato os TBIs geraram seu principal efeito esperado, que é um incremento do IED entre os países participantes do acordo. Parte dos resultados dos trabalhos empíricos já realizados evidencia esses efeitos positivos, inclusive condicionando-os a um controle da possível endogeneidade (os TBIs seriam mais frequentes nos países que já recebem mais IED), ao setor de destino do investimento (indicando se há custos irrecuperáveis nos investimentos) e a aspectos institucionais do país, sugerindo que os TBIs não são substitutos, e sim complementares às instituiçôes locais (Egger e Pfaffermayr, 2004; Neumayer e Spess, 2005; Tobin e Rose-Ackerman, 2011; Colen, Persyn e Guariso, 2016). Em contrapartida, alguns 
estudos não evidenciam tal efeito causal e apontam canais por meio dos quais a celebração de um TBI pode até mesmo reduzir o ingresso de IED (Rose-Ackerman e Tobin, 2005). ${ }^{2}$

Os custos decorrentes dos mecanismos de solução de controvérsias ocupam lugar central nas críticas aos TBIs, motivando inclusive o encerramento de vários deles. A perda de soberania seria também uma possível desvantagem de se firmar um acordo de investimento nos moldes tradicionais, em que eventuais litígios são julgados em tribunais internacionais nos quais as especificidades das leis locais não têm validade (Neumayer e Spess, 2005; Elkins, Guzman e Simmons, 2006). Além disso, com receio de serem citados em algum tribunal de arbitragem internacional, os países que são membros do acordo perdem a liberdade de implementar políticas de interesse público, mas que afetam o retorno do investimento externo realizado no âmbito do TBI. Diante de tais críticas, os novos TBIs apresentam mecanismos de solução de controvérsias com menor risco, exigem maior transparência nos tribunais de arbitragem e deixam claro que os objetivos de desenvolvimento sustentável e outros objetivos sociais náo podem ser penalizados pelos termos do TBI. ${ }^{3}$

Além desta introdução, o artigo conta com quatro seçôes. Na segunda, são apresentados conceitos relacionados aos TBIs. Em seguida, discorre-se sobre aspectos teóricos embasando a relação positiva entre fazer parte do TBI e o ingresso de IED. Críticas aos TBIs comumente encontradas na literatura também são apresentadas nessa seção. $\mathrm{Na}$ quarta seção, exibem-se algumas tendências para os TBIs, tendo em vista as vantagens e desvantagens de fazer parte desse tipo de acordo. A última seção traz algumas conclusóes.

\section{TBIS: HISTÓRICO E CONCEITOS FUNDAMENTAIS}

Um TBI é um acordo entre dois países que estabelece o tratamento dispensado ao investimento realizado num dos países por uma empresa do outro país. Como destacado no relatório de UNCTAD (2000), em 1959 foi assinado o primeiro TBI, no seu formato atual, entre a Alemanha Ocidental e o Paquistão. Inicialmente, os TBIs eram ratificados entre países exportadores de capital (países desenvolvidos) e países importadores de capital (países em desenvolvimento). O interesse do país desenvolvido no TBI era garantir segurança jurídica adicional para os investimentos de suas empresas além do que era oferecido pelas leis do país em desenvolvimento, cuja motivação em participar do TBI era utilizar o acordo como meio de atrair mais investidores externos. Todavia, esse padrão mudou desde o final da década de 1980 e, especialmente, nos anos 1990, à medida que os países em desenvolvimento e as economias em transição começaram a assinar diversos TBIs entre si. Como resultado, TBIs eram ratificados mesmo entre países importadores de capital (UNCTAD, 2000). No decorrer dos anos, os TBIs se tornaram o principal instrumento para reger as relaçóes de investimento entre países de diferentes níveis de desenvolvimento econômico (UNCTAD, 2015).

Um marco importante na história dos TBIs foi a criação do Centro Internacional para a Arbitragem de Disputas sobre Investimentos (International Centre for Settlement of Investment Disputes - ICSID) em 1965. O ICSID é uma instituição intergovernamental abrigada no Banco Mundial estabelecida sob um tratado multilateral, a Convenção sobre a Solução de Disputas sobre Investimentos entre Estados e Nacionais de Outros Estados. O ICSID tem fornecido instrumentos para a resolução de controvérsias sobre investimentos entre investidores e Estados anfitrióes. Outro

2. A literatura empírica sobre os efeitos dos TBIs sobre o IED é revisada no artigo Investimento Externo Direto na América Latina: o papel dos acordos de investimento, publicado neste volume.

3. Disponível em: <https://bit.ly/3d2Xs0k> 
exemplo de uma instituição de arbitragem internacional é a Comissão das Naçóes Unidas para o Direito Comercial Internacional (United Nations Commission on International Trade Law - Uncitral), que disponibiliza um conjunto de normas que podem regular o processo de arbitragem, mas não atuam como instituição de arbitragem (UNCTAD, 1996). As disputas entre investidor e Estado relacionadas ao TBI são decididas por um tribunal que normalmente consiste em três árbitros, cada uma das partes nomeando um deles, e o presidente é escolhido em comum acordo entre as partes.

Como mostra o gráfico 1, na década de 1990 e no início dos anos 2000, o número acumulado de TBIs cresceu expressivamente. Atualmente, existem 2.911 TBIs assinados e 2.353 ratificados (in force). Contribuiu para esse aumento a competição por investimentos externos entre países. Naçóes como a China e a Índia, com enorme potencial tanto como destino quanto como fonte de IED, expandiram rapidamente o número de tratados. Nesse período de elevado crescimento no número de acordos, o Brasil assinou alguns TBIs, mas nunca os ratificou, em razão de objeçóes, por parte do Congresso Nacional, aos termos dos acordos assinados, que, no entender do Congresso, concediam privilégios ao investidor estrangeiro em detrimento do nacional e limitavam a autonomia regulatória do Estado (Cozendey e Cavalcante, 2015; Morosini e Xavier Junior, 2015).

\section{GRÁFICO 1}

\section{Evolução do número de acordos de investimento no mundo} (Em 1 mil)

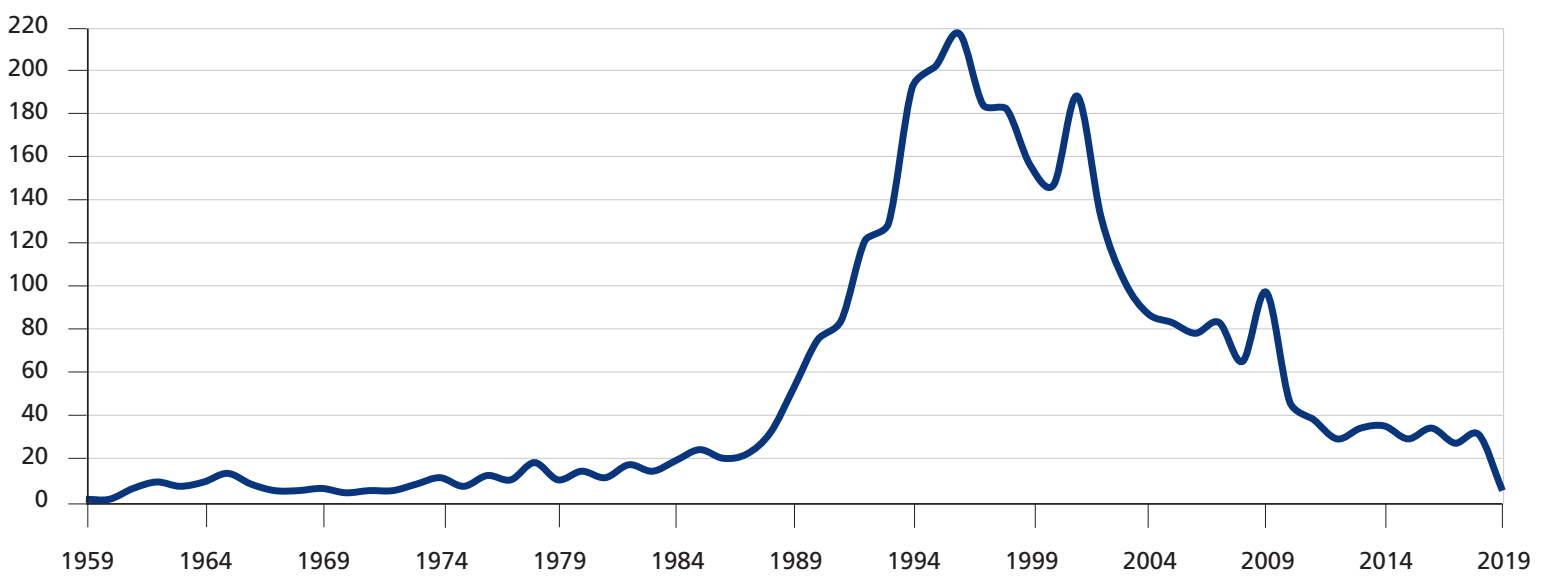

Fonte: UNCTAD (2019).

Muchlinski (2009) descreve os elementos usualmente encontrados num TBI. O TBI apresenta uma seção de apresentação do acordo (preâmbulo) em que podem ser encontrados seus propósitos e os setores da economia que se pretende beneficiar pelo tratado. Definem-se, a seguir, os investimentos que serão cobertos pelo tratado, incluindo não apenas ativos físicos mas também propriedade intelectual. Os termos do acordo também limitam investidores que podem participar dele, tornando-o restrito, por exemplo, àqueles que investem no país receptor e que possuem alguma ligaçáo de nacionalidade e residência no país contratante. Outro aspecto importante do acordo são os padróes do tratamento dado à empresa investidora. Para garantir que o investidor estrangeiro tenha tratamento equitativo e não discriminatório, em alguns casos, pode-se definir que será dispensado um tratamento ao menos táo bom quanto o dado às empresas domésticas ou um equivalente ao melhor tratamento dado a uma empresa estrangeira já estabelecida no país. Um componente-chave do acordo é a seção sobre as cláusulas de resolução de controvérsias. São esses termos que em tese garantem a proteção do direito 
de propriedade à luz do direito internacional e a compensação em caso de expropriação. Cláusulas de solução de controvérsias em TBIs podem ser divididas entre as que lidam com disputas entre os países quanto à observância e à interpretação do tratado e aquelas que lidam com disputas entre o investidor e o país anfitrião. Em ambos os casos, pode haver previsão no acordo para resolver as controvérsias através de negociação direta. Caso a negociação não solucione a discordância, parte-se para algum tribunal de arbitragem, com maior frequência seguindo as recomendaçóes do ICSID. Havendo pré-consentimento total, os TBIs concedem aos investidores estrangeiros o direito de apresentar, unilateralmente, pedidos de arbitragem internacional diretamente contra os governos, sem primeiro utilizar os recursos jurídicos internos do país.

\section{TBIS: ASPECTOS TEÓRICOS}

A seguir, serão apresentados aspectos teóricos sobre por que o TBI é capaz de atrair investimentos para um país e em que circunstâncias esse impacto pode ser potencializado. É importante destacar que os TBIs podem trazer custos para os países-membros e que esses custos podem tornar a adesão ao TBI menos atrativa ou mesmo resultar em seu cancelamento. Nesta seção, também serão exibidos alguns pontos negativos dos TBIs.

\subsection{Como o TBI estimula o IED}

De acordo com Guzman (2009), Neumayer e Spess (2005), Hallward-Driemeier (2003) e Kohler e Stähler (2016), a adoção de acordos bilaterais de investimento é resposta para problemas de hold-up (comportamento oportunista) ou de inconsistência dinâmica nos países em desenvolvimento tentando atrair IEDs. Nos problemas de inconsistência dinâmica, uma política ótima, quando avaliada numa data inicial de planejamento, não continua sendo ótima numa data posterior, embora nenhuma informaçáo nova tenha aparecido nesse meio-tempo. No caso dos IEDs, de acordo com os autores, o problema de inconsistência dinâmica decorre do fato de que, embora os países anfitrióes tenham um incentivo para prometer tratamento justo e equitativo para atrair investimentos estrangeiros, uma vez que o investimento seja estabelecido e os investidores tenham custos irreversíveis, há incentivos para o país anfitrião cobrar impostos mais elevados, restringir a repatriação de lucros, obrigar a contratação de mão de obra local, adquirir conteúdo nacional e até mesmo expropriar os ativos de investidores estrangeiros. ${ }^{4} \mathrm{Ou}$ seja, quando os investimentos já realizados envolvem custos irrecuperáveis, os anfitrióes podem extrair da empresa pelo menos até o valor desses custos sem que essa empresa tenha incentivos para encerrar suas atividades.

Como destaca Guasch (2004), um cenário típico de inconsistência dinâmica pode ocorrer nas concessóes para abastecimento de água, pois, buscando assegurar apoio popular durante uma campanha de reeleição, o governo pode impor à empresa concessionária cortes de tarifas ou não honrar os aumentos de tarifas acordados. Segundo o autor, outro cenário comum é um novo governo eleito que decida não honrar os aumentos tarifários acordados, por uma administração anterior, em um contrato de concessão, ou perseguir prioridades diferentes das da administração anterior, exigindo um novo plano de tarifas e investimentos da concessionária. Caso a empresa entenda as consequências do problema de inconsistência dinâmica antes de investir, pode optar por não investir no país estrangeiro

4. Nas décadas de 1960 e 1970, a expropriação direta era o risco mais significativo para o investimento estrangeiro. Atualmente, os meios pelos quais os países anfitriões discriminam ou expropriam o investimento estrangeiro são mais sutis (Büthe e Milner, 2008). 
ou pode manter o investimento exigindo um prêmio adicional (refletido em tarifas mais altas, por exemplo) para compensar o risco regulatório. Concomitantemente, para resolver possíveis disputas judiciais, o direito internacional não oferece um meio para que um país anfitrião faça compromissos confiáveis com um investidor de outro país. Portanto, fazer parte de um TBI e estar sujeito aos seus mecanismos de resoluçáo de disputas em caso de expropriação potencialmente protege o investidor contra um comportamento oportunista do país hospedeiro, evitando o problema de inconsistência dinâmica, que pode reduzir a rentabilidade esperada do investimento.

Kerner (2009) constrói as justificativas teóricas a respeito dos impactos positivos dos TBIs sobre o IED baseado no trabalho de Fearon (1997), em que são desenvolvidos argumentos teóricos sobre como os custos ex ante e expost associados ao não cumprimento de acordos firmados entre países podem tornar os compromissos críveis em razão de mecanismos do tipo hands-tying ou cost-sinking. Um mecanismo do tipo hands-tying atua gerando um custo em que um participante do acordo incorrerá expost se ele não cumprir o compromisso. $\mathrm{O}$ mecanismo cost-sinking atribui um custo irrecuperável ex ante a uma açáo, com o objetivo de separar participantes do acordo sinceros e náo sinceros.

Conforme destaca Kerner (2009), o TBI pode funcionar como um mecanismo hands-tying se e somente se os custos ex post de expropriação são suficientemente elevados para que os países participantes evitem fazê-lo. Em contrapartida, a assinatura do TBI pode gerar custos irrecuperáveis ex ante capazes de enviar um sinal a outros investidores não participantes do TBI. Isso pode ocorrer porque o TBI é capaz de limitar a regulação estatal e a aplicação de leis dos países receptores do investimento que poderiam ser interpretadas como expropriação. De outra forma, o risco de litígios baseado no tratamento preferencial previsto no TBI também contribui para a composição desse custo.

Com base nesses argumentos, o TBI pode impactar diretamente o IED entre os países signatários por meio do mecanismo hands-tying. Efeitos indiretos no IED ocorreriam em razáo dos custos irrecuperáveis induzidos pela assinatura de um TBI que pode ao menos gerar a expectativa de não haver expropriaçáo dos investimentos realizados por empresas de outros países que não fazem parte do acordo de investimento. Nessa direçáo, Neumayer e Spess (2005) argumentam que a assinatura de TBIs envia um sinal para potenciais investidores de que o país em desenvolvimento é geralmente sério sobre a proteção do investimento estrangeiro. É difícil afirmar, porém, o quão importante é o efeito de sinalização, que beneficia os investidores de todos os países, em comparação com o efeito de compromisso, que apenas se relaciona com investidores de países parceiros do TBI.

Para Tobin e Rose-Ackerman (2011), esse sinal se torna claro e o compromisso mais crível à medida que o número de TBIs com países desenvolvidos aumenta. Isso ocorre porque, gradativamente, mais fontes de IED são cobertas pelos mecanismos de enforcement incluídos no TBI. Acordos com outros países em desenvolvimento não enviariam esse sinal, principalmente se eles envolvem países que não são fontes prováveis de IED. Para os autores, é possível ainda que o benefício marginal de ingressar num TBI seja maior em países em desenvolvimento com melhor qualidade institucional. Os TBIs elevariam pouco o IDE nos ambientes mais arriscados e podem apresentar um efeito positivo mais perceptível para os países com níveis moderados de risco político.

Elkins, Guzman e Simmons (2006) destacam que a consolidação da reputação do país participante do TBI passa por acatar as decisóes dos tribunais internacionais definidos no tratado. Os autores ressaltam que, havendo alguma disputa judicial com um investidor no âmbito do TBI, o país anfitriáo não pode impedir o processo judicial de avançar, nem controlar a decisão final do 
tribunal internacional de arbitragem. $\mathrm{O}$ tribunal internacional pode exigir o pagamento por uma expropriação caso o país anfitrião esteja violando suas obrigaçóes acordadas no tratado. Recusar-se a cumprir a determinação do tribunal internacional poderia gerar danos profundos à reputação do país que recebeu o investimento, que certamente sofreria as consequências negativas de ser um parceiro econômico não confiável.

De acordo com Tobin e Rose-Ackerman (2011), dois países com fundamentos econômicos semelhantes atrairiam níveis variados de IED, dependendo do número de TBIs que eles têm em vigor, e o impacto marginal dos TBIs seria maior para países com fundamentos econômicos mais fortes. No entanto, um país com muitos TBIs, mas com baixa renda, crescimento lento e economia fechada, provavelmente não atrairá muito IDE, e os TBIs pouco podem fazer para melhorar essa situação, já que, embora afetem o risco de investimento, eles teriam pouco ou nenhum impacto sobre os fundamentos da economia. Segundo os autores, os TBIs seriam complementares aos aspectos locais tradicionalmente utilizados como determinantes dos IEDs, tais como tamanho do mercado e dotação de fatores. Tobin e Rose-Ackerman (2011) sugerem, por exemplo, que o efeito positivo que as dotaçóes geram no IED pode ser potencializado quando o país ratifica mais TBIs. Combinados com acordos de livre comércio, os TBIs podem também elevar os IEDs.

\subsection{Críticas aos TBls}

Não há consenso teórico sobre o papel desempenhado pelos TBIs na determinação dos IEDs. Para Yackee (2009), os TBIs têm pouca relevância na explicação da decisão de investimento de uma empresa multinacional por três motivos. Em primeiro lugar, os possíveis investidores não conhecem a existência dos TBIs no momento de decidir em que país investir - nessa mesma direção, Poulsen (2010) destaca que investidores procuram informaçóes sobre os TBIs com maior frequência quando surge alguma disputa, e não quando estão planejando seus investimentos. Em segundo lugar, Yackee (2009) acredita não haver razóes para esperar que os TBIs sejam mais eficazes do que a legislaçáo local na resoluçáo do problema de compromissos críveis nos contratos de investimento. Investimentos envolvendo elevados custos irrecuperáveis, como as concessóes de infraestrutura, são sempre cobertos por contratos detalhados, tornando os TBIs desnecessários. Em último lugar, de acordo com Guasch (2004), o prêmio de risco regulatório em projetos de infraestrutura (abastecimento de água, por exemplo) causado por contratos sem comprometimento crível é baixo, girando em torno de $2 \%$ a $6 \%$ do custo do capital. Não seria necessário, portanto, realizar um TBI para minimizar um possível risco regulatório que adicionaria pouco custo ao investimento.

Os TBIs também podem ser vistos por uma perspectiva mais pessimista, indicando possíveis efeitos negativos sobre o IED. De acordo com Tobin e Rose-Ackerman (2011), pode haver circunstâncias em que o TBI estimula apenas o IED do país de origem do investimento para países com os quais ele tem tal acordo. Ao mesmo tempo, o IED de outros países ou mesmo o investimento de empresas domésticas podem cair em razão do tratamento mais favorável concedido aos investimentos de uma fonte particular.

Um aspecto bastante crítico no TBI é o rigor de alguns mecanismos de solução de disputas entre investidor e Estado (investor-state dispute settlement - ISDS). Contribuiu para essa visáo crítica dos TBIs o aumento no número de casos em que as ISDS foram acionadas: de 326, em 2008, para 942 casos conhecidos, no final de 2018, envolvendo países desenvolvidos e em desenvolvimento como 
acusados. Desse total, 61\% das disputas foram favoráveis ao investidor e 39\% ao Estado anfitrião. ${ }^{5}$ Para Poulsen e Aisbett (2013), os países em desenvolvimento percebem os custos de participar dos TBIs quando começam a ser questionados por meio das ISDS e ao se verem obrigados a pagar vultosas indenizaçóes às empresas que investiram no país em razão do TBI. Como é destacado em documento de UNCTAD (2015), há receio de que o atual mecanismo de solução de controvérsias exponha os Estados receptores de investimentos externos a riscos jurídicos e financeiros adicionais, frequentemente imprevisíveis no momento da entrada no acordo, sem trazer necessariamente quaisquer benefícios em termos de fluxos adicionais de IED. Em alguns casos, são concedidos mais aos investidores estrangeiros direitos, em relação à solução de controvérsias, que aos investidores domésticos. Tais desequilíbrios entre Estado e investidor se manifestam ainda na concepção dos TBIs. Testes empíricos realizados por Allee e Peinhardt (2014) revelam que tratados de investimento contêm ISDS mais rígidas quando o parceiro exportador de capital do tratado tem considerável poder de barganha e suas empresas domésticas preferem tais acordos.

Há estudos indicando que as comissóes de julgamento podem favorecer mais o investidor que o Estado. Esse viés, segundo Nunnenkamp (2017), tende a penalizar mais os países em desenvolvimento que os de renda alta. Segundo o autor, uma inspeção mais rigorosa nos dados sobre resultados dos comitês arbitrais sugere que isso se deve em grande parte aos presidentes de tribunais que são mais tendenciosos em favor dos investidores que dos países em desenvolvimento. Representantes dos próprios Estados nos tribunais parecem ter menos influência sobre os resultados da ISDS. Segundo Donaubauer, Neumayer e Nunnenkamp (2018), se o presidente do comitê de arbitragem já foi representante do investidor em outras ocasiôes, é mais provável que sua decisão, que normalmente tende a ser a de desempate, seja a favor do investidor.

Buscando evitar disputas com os investidores, os países em desenvolvimento tentam manter a conformidade de suas políticas com o estabelecido no TBI. Como consequência, conforme Neumayer e Spess (2005) e Elkins, Guzman e Simmons (2006) destacam, é enorme a extensão da interferência na soberania reguladora doméstica a que os países em desenvolvimento sucumbem ao assinar TBIs e se submeterem às cláusulas da ISDS. Ao ratificarem um TBI, os países em desenvolvimento podem estar "trocando a soberania pela credibilidade". Dependendo da forma como esses mecanismos são definidos no tratado, virtualmente qualquer regulamentação de política pública pode ser potencialmente contestada por meio do mecanismo de solução de controvérsias do tratado, desde que afete os investidores estrangeiros, mesmo que tal regulamentação seja de interesse público. Isso acontece quando os investidores consideram que a política pública implementada pelo Estado anfitriâo resultou numa expropriaçáo indireta, que seria uma perda de rentabilidade do investimento em razão de alguma ação praticada pelo Estado. Em 2010, por exemplo, a empresa Philip Morris entendeu que a política antitabagismo do Uruguai prejudicaria suas vendas. Em razão disso, o investidor registrou uma reclamação contra o país no ICSID $^{6}$ sob os termos do TBI Suíça-Uruguai solicitando uma indenização para compensar suas possíveis perdas. Nesse caso, o ICSID decidiu em favor do Estado, obrigando inclusive a empresa a arcar com os custos processuais que o Uruguai teve no decorrer do processo, mas certamente o processo todo foi uma ameaça a uma importante política nacional.

5. Disponível em: $<$ https://bit.ly/3d2Xs0k>.

6. Caso ICSID no ARB/10/7. 
A esse conjunto de críticas, Hallward-Driemeier (2003) adiciona que, à medida que o potencial para o recurso legal sob os TBIs for mais amplamente conhecido pelas empresas, a importância dos TBIs na seleção de um local para realizar o investimento pode se tornar mais importante e levar a problemas de risco moral e seleção adversa. Se os investidores acreditam que há uma chance de litígio bem-sucedido contra o governo anfitriáo e que eles são protegidos contra riscos substanciais, as empresas podem se esforçar menos para cumprir o estabelecido no acordo. Em contrapartida, as empresas com maior probabilidade de investir no país receptor podem ser aquelas mais interessadas em buscar todos os recursos legais para obter algum benefício. Esse comportamento do investidor, além de reduzir a eficiência do investimento externo, pode elevar os custos dos países receptores para resolver os litígios em tribunais internacionais.

A procura dos países em desenvolvimento por fazer parte de acordos de investimento pode significar um processo de concorrência entre países por mais IEDs (Elkins, Guzman e Simmons, 2006; Guzman, 2009). O incentivo individual para elevar as receitas de investimento por meio do TBI e se beneficiar dos efeitos gerados pelo IED leva os países a ratificarem TBIs para disputar com outros que possuem tratados de investimento já em andamento. A estratégia concorrencial entre países por investimentos não se limita à busca por participar de TBIs. A esse respeito, Neumayer, Nunnenkamp e Roy (2016) apontam que existe também "contágio" dos termos dos acordos, em particular nas cláusulas de resolução de controvérsias. Acordos de países em desenvolvimento com países desenvolvidos que contenham cláusulas rígidas em favor do investidor tendem a ser replicados em acordos de outros países em desenvolvimento. Com relação à predisposição para aceitar a perda de soberania, Allee e Peinhardt (2010) argumentam que, mesmo os governos anfitrióes do investimento não concordando com as condiçôes rígidas para a resoluçáo de controvérsias em tribunais internacionais, principalmente quando os custos de soberania são altos, eles são mais propensos a concordar com tais cláusulas quando são mais dependentes de suas relaçóes com outros países. Ao fim dessas interaçóes, os países em desenvolvimento, principalmente aqueles mais dependentes de IED, acabam por escolher assinar TBIs contendo cláusulas mais rígidas beneficiando o investidor externo diante de uma possível disputa com o estado anfitriáo. Nessa situação, esses países tendem a perder o excedente do investimento ou podem estar incorrendo em custos ao desistir de instrumentos domésticos de promoçáo de desenvolvimento econômico e social, tais como os requerimentos de performance, a contratação de mão de obra local, a tributação etc., para atrair investidores por meio dos TBIs.

No quadro 1, elaborado pela Conferência das Naçóes Unidas sobre Comércio e Desenvolvimento (United Nations Conference on Trade and Development - UNCTAD), está a síntese das vantagens e desvantagens de fazer parte de um TBI. As desvantagens elencadas certamente colocam em dúvida se os custos do TBI são compensados pelos seus benefícios. Como será visto mais adiante, existe em curso um grande esforço dos países e de organismos como a UNCTAD de definir um novo modelo de TBI que ao menos diminua a exposição dos países em desenvolvimento aos riscos associados à ratificação do tratado e que também permita aos países a liberdade de colocar em prática suas políticas de interesse público, sem o receio do acionamento num comitê de arbitragem por, supostamente, ter afetado negativamente o fluxo de caixa de uma empresa. 
QUADRO 1

Vantagens e desvantagens do TBI

\begin{tabular}{|c|c|}
\hline Vantagens & Desvantagens \\
\hline Contribui para um ambiente favorável ao investimento. & Não garante a entrada de investimentos adicionais. \\
\hline $\begin{array}{l}\text { Contribui para fomentar e expandir a cooperação econômica e política } \\
\text { entre as partes contratantes. }\end{array}$ & $\begin{array}{l}\text { Pode afetar negativamente o direito soberano dos países anfitriões de } \\
\text { regular o interesse público. }\end{array}$ \\
\hline $\begin{array}{l}\text { Contribui para a estabilidade e previsibilidade do quadro político, promove } \\
\text { a boa governança e o estado de direito. }\end{array}$ & $\begin{array}{l}\text { Expõe os Estados anfitriões aos tribunais internacionais de resolução de } \\
\text { controvérsias e aos riscos financeiros associados. }\end{array}$ \\
\hline $\begin{array}{l}\text { Fornece direitos de proteção que sejam independentes da legislação } \\
\text { interna dos países anfitriões (superioridade do direito internacional sobre } \\
\text { a lei nacional). }\end{array}$ & Privilegia os investidores estrangeiros sobre os investidores domésticos. \\
\hline $\begin{array}{l}\text { Em comparação com o direito internacional consuetudinário, melhora a } \\
\text { segurança jurídica, uma vez que os direitos de proteção são especificados } \\
\text { no tratado. }\end{array}$ & Fornece apenas os direitos dos investidores, não estabelecendo obrigações. \\
\hline Reduz os riscos políticos de investir no exterior. & $\begin{array}{l}\text { Reflete um resultado negociado que é influenciado pelo poder de barganha } \\
\text { das partes negociadoras. }\end{array}$ \\
\hline Pode facilitar a concessão de garantias de investimento pelo país de origem. & $\begin{array}{l}0 \text { acordo de investimento pode resultar em obrigações sobrepostas e } \\
\text { inconsistentes das partes contratantes. }\end{array}$ \\
\hline Ajuda a evitar a politização de disputas de investimento. & É difícil alterar em caso de mudança de circunstâncias econômicas. \\
\hline
\end{tabular}

Fonte: UNCTAD (2015)

\section{TENDÊNCIAS PARA OS TBIS}

A série histórica sobre o número de TBIs assinados revela uma tendência de redução de novos acordos a partir de 2009. Em parte, essa redução é resultado do encerramento de alguns acordos de investimento, envolvendo, por exemplo, África do Sul, Equador, Índia e Indonésia ${ }^{7}$ (Cervantes-Knox e Thomas, 2017). Com efeito, o ano de 2017 foi concluído com o menor número de novos acordos internacionais de investimento desde 1983 e, pela primeira vez, o número de tratados com prazo encerrado superou o número de novas conclusôes de acordos de investimento, sinalizando um período de reflexão e revisão de políticas de investimento internacional. ${ }^{8}$

No centro das decisôes de encerramento de TBIs estão os mecanismos de ISDS, que, como já foi discutido, têm resultado em um número crescente de reclamaçóes junto ao ICSID. Segundo documento de acompanhamento das políticas de investimento da UNCTAD, a maioria dos novos acordos firmados em 2018 já traz mudanças importantes nesse ponto. ${ }^{9}$ As mudanças mais frequentes nos acordos são cláusulas estabelecendo que devem ser esgotadas as possibilidades locais de resolução das disputas antes de o processo de arbitragem num tribunal internacional começar e que deve haver aumento do controle dos processos por parte do governo e de medidas que buscam julgamentos mais transparentes e imparciais. Em alguns novos tratados, optou-se simplesmente por não incluir a possibilidade de submeter uma disputa entre investidor e Estado a um tribunal de arbitragem internacional. Bernasconi-Osterwalder (2015) ressalta ainda que reformulaçóes nas ISDS envolvem também a criação de um mecanismo de apelação, em que as decisôes arbitrais poderiam ser revistas e totalmente modificadas. Além disso, em alguns acordos, optou-se por manter apenas o mecanismo de disputa do tipo Estado-Estado.

7. Disponível em: $<$ https://bit.ly/3d2Xs0k>.

8. Disponível em: <https://bit.ly/3xl1qu5>.

9. Há também iniciativas de modernização dos tratados antigos, com o propósito de contemplar neles essas novas tendências na normatização das disputas entre investidor e Estado. A China, por exemplo, modernizou recentemente 32 dos seus 144 TBls (Huang, 2018). 
Outras mudanças importantes também visam minimizar a exposição do país hospedeiro à arbitragem internacional, definindo com maior clareza o que seria expropriação indireta, limitando os tipos de ativos que constituem o IED e excluindo do escopo do tratado as políticas públicas adotadas por governos locais. Também fazem parte dos novos modelos cláusulas com orientação pró-desenvolvimento sustentável, estabelecendo que as partes não podem abrir mão de políticas relacionadas à saúde, à segurança e à preservaçáo do meio ambiente para atrair investimento externo (UNCTAD, 2019).

Na questáo dos acordos de investimento, o Brasil caminha na direçáo de TBIs com instrumentos de resoluçáo de disputas mais brandos. Apresentado em 2015, o modelo de acordo bilateral de investimento brasileiro, chamado de Acordo de Cooperação e Facilitação de Investimentos (ACFI), tem formato inovador e, diferentemente dos TBIs tradicionais, que são voltados para a proteção do investidor, se concentra principalmente na facilitação de cooperação e investimento entre as partes (Brauch, 2015). Ademais, o ACFI propóe o estabelecimento de pontos focais, ou ombudsmen, em cada Estado-parte, além da criação de um comitê conjunto intergovernamental. Essas instâncias podem ser consideradas o núcleo institucional do acordo, pois contribuem para a concretização dos compromissos firmados e para o fortalecimento do diálogo entre as partes em matéria de investimento. ${ }^{10}$ Desde 2015, o Brasil já celebrou acordos de investimento nos moldes dos ACFIs com países da América do Sul e da África e com o México.

É importante destacar que o Brasil experimentou um elevado crescimento no ingresso de IED nos últimos anos. De acordo com Jadhav (2012), a maior parte do IDE no período recente nas economias do BRICS ${ }^{11}$ foi motivada pelo propósito de busca do mercado. Ademais, o país aparenta ser um destino confiável para o investimento externo, uma vez que investidores estrangeiros são bem protegidos pelo sistema jurídico nacional. A exemplo disso, a Lei no 8.987/1995 permite que sejam previstos mecanismos de solução de controvérsias nos contratos de concessão de serviços públicos caracterizados por custos elevados irrecuperáveis, propiciando alguma proteção jurídica previsível ao investidor externo. Dessa forma, mesmo sem ratificar seus TBIs na década de 1990, o Brasil conseguiu atrair vultosos montantes de IED para o setor de distribuição de energia elétrica, conforme apontam Andrade, Silva Filho e Leite (2017). Segundo os autores, as mudanças regulatórias para o IED no Brasil promovidas entre 2005 e 2006 - que, entre outros aspectos, reduziu o risco cambial para empresas estrangeiras no país - podem ter contribuído para o país ser um dos principais destinos de investimento no mundo. Isso não significa, porém, que o ingresso de IED no Brasil não foi impactado pela inexistência de acordos de investimento em vigência no país durante o período de elevada expansão mundial no número de TBIs. Certamente, um estudo empírico ajudaria a esclarecer em que medida o país receberia ainda mais investimentos externos do que recebeu caso tivesse ratificado seus acordos.

\section{CONCLUSÕES}

Os TBIs se tornaram um dos principais mecanismos para a atração de IED nos países em desenvolvimento nas últimas décadas. Segundo a teoria, fazer parte do TBI e cumprir seus termos daria um sinal claro aos investidores internacionais de que seria seguro investir no país. Todavia, esse tipo de acordo

10. Disponível em: <https://bit.ly/3y5CLZJ>.

11. Brasil, Rússia, Índia, China e África do Sul. 
está sujeito a várias críticas. Uma delas diz respeito à possível perda de soberania para implementar políticas públicas de interesse da sociedade em troca da participação num acordo de investimento. A crítica mais recorrente deriva dos mecanismos de ISDS. Principalmente quando no acordo não está claro o significado de expropriação, há margem para os investidores acionarem os Estados receptores em tribunais internacionais, gerando custos jurídicos não previstos e também uma possível perda de credibilidade. A falta de transparência nas decisóes dos tribunais internacionais, a maioria delas sendo a favor do investidor, também é um aspecto negativo para os TBIs.

Além disso, o uso de TBIs como instrumento de concorrência por IED entre países pode levar a uma situação socialmente indesejável, na medida em que são inseridos nos acordos termos favorecendo demasiadamente o investidor, em detrimento da soberania para regulamentar a atividade econômica e implementar políticas de interesse social. Alguns autores (Guzman, 2009) chegam à conclusão de que a concorrência por IED faz os países se defrontarem com um problema do tipo dilema dos prisioneiros: os países em desenvolvimento poderiam estar em vantagem se não adotassem o TBI como estratégia, mas acabam por assinar esses acordos, com receio de perder oportunidades de IED.

Em razão principalmente dos problemas resultantes dos mecanismos de solução de controvérsias, está em curso uma reforma no formato dos TBIs, seja para os novos acordos, seja para os antigos que estão sendo modernizados. Nas linhas gerais desse novo formato de TBI está a melhor definição do que deve ser considerado como expropriação indireta e também de termos que garantam o direito de regular, gerando um bom ambiente de investimento sem perder o direito de criar regulaçóes que permitam perseguir objetivos de desenvolvimento sustentável e outros objetivos socioeconômicos.

Os resultados que esses novos acordos estáo gerando em termos de ingressos de IED e desenvolvimento econômico certamente serão objeto de análise em estudos empíricos futuros, à medida que novos dados sobre os IEDs vão sendo publicados. Em face da grande tendência nos novos TBIs de náo haver sacrifício de políticas de interesse público e ao mesmo tempo haver garantias de um bom ambiente de investimento para empresas estrangeiras, espera-se que a competição entre países por meio dos TBIs resulte numa distribuição de IED cujas recompensas sejam mais bem aceitas pela sociedade.

\section{REFERÊNCIAS}

ALLEE, T.; PEINHARDT, C. Delegating differences: bilateral investment treaties and bargaining over dispute resolution provisions. International Studies Quarterly, v. 54, n. 1, p. 1-26, 2010.

Evaluating three explanations for the design of bilateral investment treaties. World Politics, v. 66, n. 1, p. 47-87, 2014.

ANDRADE, I. O.; SILVA FILHO, E. B.; LEITE, A. W. Análise da regulação dos investimentos estrangeiros diretos no Brasil. In: MESSA, A.; OLIVEIRA, I. T. M. (Org.). A política comercial brasileira em análise. Brasília: Ipea, 2017.

BÉNASSY-QUÉRÉ, A.; COUPET, M.; MAYER, T. Institutional determinants of foreign direct investment. World Economy, v. 30, n. 5, p. 764-782, 2007.

BERNASCONI-OSTERWALDER, N. Rethinking investment-related dispute settlement. Investment Treaty News, v. 6, n. 2, 2015.

BLONIGEN, B. A. A review of the empirical literature on FDI determinants. Atlantic Economic Journal, v. 33, n. 4, p. 383-403, 2005. 
BRAUCH, M. D. The Brazil-Mozambique and Brazil-Angola Cooperation and Investment Facilitation Agreements (CIFAs): a descriptive overview. Investment Treaty News, v. 6, n. 2, 2015.

BUCHANAN, B. G.; LE, Q. V.; RISHI, M. Foreign direct investment and institutional quality: some empirical evidence. International Review of Financial Analysis, v. 21, p. 81-89, 2012.

BÜTHE, T.; MILNER, H. V. The politics of foreign direct investment into developing countries: increasing FDI through international trade agreements? American Journal of Political Science, v. 52, n. 4, p. 741-762, 2008.

CERVANTES-KNOX, K.; THOMAS, E. Ecuador terminates 12 BITs - a growing trend of reconsideration of traditional investment treaties? International arbitration alert. [s.l.]: DLA Piper, 15 May 2017.

COLEN, L.; PERSYN, D.; GUARISO, A. Bilateral investment treaties and FDI: does the sector matter? World Development, v. 83, p. 193-206, 2016.

COZENDEY, C. M. B.; CAVALCANTE, P. M. Novas perspectivas para acordos internacionais de investimentos o Acordo de Cooperação e Facilitação de Investimentos (ACFI). Cadernos de Política Exterior, Brasília, v. 1, n. 2, p. 87-109, 2015.

DONAUBAUER, J.; NEUMAYER, E.; NUNNENKAMP, P. Winning or losing in investor-to-state dispute resolution: the role of arbitrator bias and experience. Review of International Economics, v. 26, n. 4, p. 892-916, 2018.

EGGER, P.; PFAFFERMAYR, M. The impact of bilateral investment treaties on foreign direct investment. Journal of Comparative Economics, v. 32, n. 4, p. 788-804, 2004.

ELKINS, Z.; GUZMAN, A. T.; SIMMONS, B. A. Competing for capital: the diffusion of bilateral investment treaties, 1960-2000. International Organization, v. 60, n. 4, p. 811-846, 2006.

FEARON, J. D. Signaling foreign policy interests: tying hands versus sinking costs. Journal of Conflict Resolution, v. 41, n. 1, p. 68-90, 1997.

GUASCH, J. L. Granting and renegotiating infrastructure concessions: doing it right. Washington: The World Bank, 2004. (WBI Development Studies).

GUZMAN, A. T. Explaining the popularity of bilateral investment treaties. In: SAUVANT, K. P.; SACHS, L. E. The effect of treaties in foreign direct investment: bilateral investment treaties, double taxation treaties, and investment flows. Oxford: Oxford University Press, 2009. p. 73-98.

HALLWARD-DRIEMEIER, M. Do bilateral investment treaties attract foreign direct investment? Only a bit... and they could bite. Washington: World Bank Group, 2003. (Policy Research Working Paper, n. WPS 3121).

HUANG, J. J. Procedural models to upgrade BITs: China's experience. Leiden Journal of International Law, v. 31, n. 1, p. 93-115, 2018.

JADHAV, P. Determinants of foreign direct investment in BRICS economies: analysis of economic, institutional and political factor. Procedia-Social and Behavioral Sciences, v. 37, p. 5-14, 2012.

JOHNSON, L.; SACHS, L. International investment agreements, 2011-2012: a review of trends and new approaches. In: BJORKLUND, A. (Ed.). Yearbook on international investment law and policy. Oxford: Oxford University Press, 2014. p. 219-271.

KERNER, A. Why should I believe you? The costs and consequences of bilateral investment treaties. International Studies Quarterly, v. 53, n. 1, p. 73-102, 2009.

KOHLER, W.; STÄHLER, F. The economics of investor protection: ISDS versus national treatment. Journal of International Economics, v. 121, n. 2, 2016. 
MOROSINI, F. C.; XAVIER JUNIOR, E. C. X. Regulação do investimento estrangeiro direto no Brasil: da resistência aos tratados bilaterais de investimento à emergência de um novo modelo regulatório. Revista de Direito Internacional, v. 12, n. 2, 2015.

MUCHLINSKI, P. The framework of investment protection: the content of BITs. In: SAUVANT, K. P.; SACHS, L. E. The effect of treaties in foreign direct investment: bilateral investment treaties, double taxation treaties, and investment flows. Oxford: Oxford University Press, 2009. p. 37-71.

NEUMAYER, E.; NUNNENKAMP, P.; ROY, M. Are stricter investment rules contagious? Host country competition for foreign direct investment through international agreements. Review of World Economics, v. 152, n. 1, p. 177-213, 2016.

NEUMAYER, E.; SPESS, L. Do bilateral investment treaties increase foreign direct investment to developing countries? World Development, v. 33, n. 10, p. 1567-1585, 2005.

NUNNENKAMP, P. Biased arbitrators and tribunal decisions against developing countries: stylized facts on investor-state dispute settlement. Journal of International Development, v. 29, n. 6, p. 851-854, 2017.

POULSEN, L. N. S. The importance of BITs for foreign direct investment and political risk insurance: revisiting the evidence. In: SAUVANT, K. P. Yearbook on international investment law and policy 2009-2010. Oxford: Oxford University Press, 2010. p. 539-574.

POULSEN, L. N. S.; AISBETT, E. When the claim hits: bilateral investment treaties and bounded rational learning. World Politics, v. 65, n. 2, p. 273-313, 2013.

ROSE-ACKERMAN, S.; TOBIN, J. Foreign direct investment and the business environment in developing countries: the impact of bilateral investment treaties. Yale Law and Economics Research Paper, n. 293, 2005.

TOBIN, J. L.; ROSE-ACKERMAN, S. When BITs have some bite: the political-economic environment for bilateral investment treaties. Review of International Organizations, v. 6, n. 1, p. 1-32, 2011.

UNCTAD - UNITED NATIONS CONFERENCE ON TRADE AND DEVELOPMENT. International investment instruments: a compendium. New York; Geneva: United Nations, 1996. v. 1.

Bilateral investment treaties: 1959-1999. New York; Geneva: United Nations, 2000.

World investment report 2015: reforming international investment governance. New York; Geneva: United Nations, 2015.

UNCTAD's reform package for the international investment regime. New York; Geneva: United Nations, 2018a.

Recent developments in the international investment regime. IIA Issues Notes, n. 1, p. 1-11, May 2018b.

YACKEE, J. W. Do BITs really work? Revisiting the empirical link between investment treaties and foreign direct investment. In: SAUVANT, K. P.; SACHS, L. E. The effect of treaties in foreign direct investment: bilateral investment treaties, double taxation treaties, and investment flows. Oxford: Oxford University Press, 2009. p. 379-394. 